\title{
Solubility and net exchange of calcium, magnesium and phosphorus in digesta flowing along the gut of the sheep
}

\author{
By D. BEN-GHEDALIA, H. TAGARI, S. ZAMWEL AND \\ A. BONDI \\ Department of Animal Nutrition and Agricultural Biochemistry, \\ The Hebrew University, Faculty of Agriculture, Rehovot, Israel
}

$$
\text { (Received } 9 \text { May } 1974 \text { - Accepted } 27 \text { fune 1974) }
$$

\footnotetext{
I. The changes in the solubility of calcium, magnesium and phosphorus in digesta flowing along the intestinal tract and the net movement across the intestinal wall of these elements were determined in six rams, each equipped with three $\mathrm{T}$-shaped cannulas; cannulas were placed in a total of six different sites of the small intestine. $\mathrm{Cr}_{2} \mathrm{O}_{3}$ was used as a marker substance to measure the rate of flow of the digesta.

2. The concentrations of soluble $\mathrm{Ca}, \mathrm{Mg}$ and $\mathrm{P}$ decreased as digesta moved along the intestine. The greatest fall in soluble $\mathrm{Ca}$ occurred after the first $3 \mathrm{~m}$ of the intestine, while a significant decrease in soluble $\mathrm{Mg}$ was found only at $\mathrm{I}_{5}$ and $25 \mathrm{~m}$ from the pylorus. The concentration of soluble $P$ in digesta decreased until the $7 \mathrm{~m}$ site and then remained stable. In the faeces, the level of soluble $\mathrm{Mg}$ was approximately 4 times higher than, and that of $\mathrm{Ca}$ equal to, the levels of $\mathrm{Mg}$ and $\mathrm{Ca}$ found in digesta flowing through the upper intestine. Unlike $\mathrm{Ca}$ and $\mathrm{Mg}$, a very low concentration of soluble $\mathrm{P}$ was found in the faeces.

3. In the duodenum, 84,78 and $62 \%$ of the total $\mathrm{Ca}, \mathrm{Mg}$ and $\mathrm{P}$ respectively were soluble, whereas in the digesta flowing through the terminal ileum the corresponding values were $3 \cdot 2,7 \cdot 2$ and $19 \%$ for $\mathrm{Ca}, \mathrm{Mg}$ and $\mathrm{P}$ respectively.

4. The forestomachs and the colon were found to be the main sites of $\mathrm{Mg}$ net absorption; I.I $2 \mathrm{mmol} / \mathrm{h}$ was apparently absorbed from the stomach and $\mathrm{I} \cdot 05 \mathrm{mmol} / \mathrm{h}$ from the colon. The upper small intestine ( $\mathrm{I}-3 \mathrm{~m}$ from the pylorus) appeared to be the major site of $\mathrm{Ca}$ and $\mathrm{P}$ absorption.

5. In the last $10 \mathrm{~m}$ of the small intestine, considerable amounts of minerals were secreted; $4.70,0.96$ and $\mathrm{I} .85 \mathrm{mmol} \mathrm{Ca}, \mathrm{Mg}$ and $\mathrm{P} / \mathrm{h}$ respectively were added to the digesta flowing between 15 and $25 \mathrm{~m}$ from the pylorus. The effect of the increase in the $\mathrm{pH}$ of digesta along the small intestine on the solubility of these minerals is discussed.
}

Absorption of calcium, magnesium and phosphorus in the gut of the sheep has been estimated using animals equipped with duodenal and ileal re-entrant cannulas (Bruce, Goodall, Kay, Phillipson \& Vowles, 1966; Pfeffer, Thompson \& Armstrong, 1970), and by radioisotope techniques (Wright, I955; Jones \& Mackie, 1959; Field, 1961). There is little information, however, concerning the movement of these minerals at sites along the small intestine.

In contrast to the situation in man and other single-stomached animals, the $\mathrm{pH}$ of material flowing through the upper section of the sheep's small intestine remains acidic (Kay, I969; Ben-Ghedalia, Tagari, Bondi \& Tadmor, 1974) and this may affect the absorption of $\mathrm{Ca}, \mathrm{Mg}$ and $\mathrm{P}$. Simple diffusion has been suggested as the main mechanism of $\mathrm{Ca}$ and $\mathrm{Mg}$ absorption in the sheep (Phillipson \& Storry, 1965) and he rat (Aldor \& Moore, 1970). Information on changes in the concentrations and proportions of soluble $\mathrm{Ca}, \mathrm{Mg}$ and $\mathrm{P}$ at sites along the small intestine may help in understanding the mechanisms of absorption.

There are conflicting reports on the effect of dietary $\mathrm{Ca}: \mathrm{P}$ ratio on $\mathrm{P}$ absorption in 
Table I. Calcium, magnesium and phosphorus contents of the foodstuffs given to sheep (mmol/kg air-dried material)

\begin{tabular}{|c|c|c|}
\hline Foodstuff & $\mathrm{Ca}$ & $\mathrm{Mg}$ \\
\hline $\begin{array}{l}\text { Concentrate* } \\
\text { Vetch (Vicia sativa L.) hav }\end{array}$ & $45^{\circ}$ & 87 \\
\hline
\end{tabular}

* Contained (per kg): $250 \mathrm{~g}$ barley, $250 \mathrm{~g}$ maize, $250 \mathrm{~g}$ wheat, $150 \mathrm{~g}$ cottonseed hulls, $50 \mathrm{~g}$ cottonseed meal, $5 \circ \mathrm{g}$ mineral mixture, $1200 \mu \mathrm{g}$ retinol and $10 \mu \mathrm{g}$ ergocalciferol.

ruminants (Young, Lofgreen \& Luick, 1966; Ricketts, Weinman, Campbell \& Thumbleson, 1970). The subject has considerable practical as well as scientific importance as diets based upon $\mathrm{Ca}$-rich forages are widely used. By following the fate of $\mathrm{Ca}$ and $P$ in digesta passing along the intestine of the sheep, a better understanding of the interactions between $\mathrm{Ca}$ and $\mathrm{P}$ in the gut might be achieved.

The studies in this paper relate to the net exchange of $\mathrm{Ca}, \mathrm{Mg}$ and $\mathrm{P}$ in different sections of the gastrointestinal tract of the sheep and to the changes in the solubility of these elements along the gut. The experiment was done with sheep that were cannulated at different sites along the small intestine and given a diet with a high $\mathrm{Ca}: \mathrm{P}$ ratio.

\section{EXPERIMENTAL}

\section{Animals, feeding and sampling}

Generally, the sheep, diets and the cannulation procedures were the same as those described previously (Ben-Ghedalia et al. 1974). Six Awassi rams, each cannulated with three T-shaped Perspex cannulas, which involved six different sites along the small intestine, were used. The sites of cannulation were: $0.05, \mathrm{I}, 3,7, \mathrm{I} 5$ and $25 \mathrm{~m}$ from the pylorus, the most posterior site of cannulation being located approximately $0.2 \mathrm{~m}$ from the ileo-caecal junction. Unfortunately, two of the rams which were equipped with cannulas at the $7 \mathrm{~m}$ site rejected the cannulas at the beginning of the experiment. The rejection was accompanied by a slight inflammation, after which the site of rejection healed up within 2 weeks and the experiment, which had been interrupted, began again.

$\mathrm{Cr}_{2} \mathrm{O}_{3}$-impregnated paper $(6 \mathrm{~g} / \mathrm{d})$ was used as a reference material to estimate the flow of digesta and excretion of faeces. The marker was given twice daily before half the daily ration (600 g concentrate mixture and $400 \mathrm{~g}$ vetch (Vicia sativa L.) hay/d) at 07.30 and 19.30 hours. The content of $\mathrm{Ca}, \mathrm{Mg}$ and $\mathrm{P}$ in the feeds is given in Table $\mathrm{r}$. Tap-water was offered ad lib. and intake was not recorded, but our previous observations on their drinking behaviour suggested that for sheep kept on similar diets during the same season (spring), the water intake would be in the range $\mathrm{I}-31 / \mathrm{d}$. The content of $\mathrm{Ca}, \mathrm{Mg}$ and $\mathrm{P}$ in the drinking-water was $2.83,0.53$ and $2.10 \mathrm{mmol} / \mathrm{l}$ respectively. The influence of the limited amounts of these elements in drinking-water should be considered with reference to the net exchange between the mouth and the duodenal cannula.

Samples, each of about $25 \mathrm{ml}$ digesta, were taken from each cannula six times daily 
for 4 successive days $I, 3,5,7,9$ and I $h$ after the morning feed. The samples obtained on the 4 successive days from each cannula were pooled for each sheep. The pooled samples were kept frozen at $-20^{\circ}$ until used for total and soluble $\mathrm{Ca}, \mathrm{Mg}$ and $\mathrm{P}$ analysis.

\section{Analytical procedures}

For total $\mathrm{Ca}, \mathrm{Mg}$ and $\mathrm{P}$ determination, foodstuffs, freeze-dried digesta and faeces were ashed at $500^{\circ}$ for $2 \mathrm{~h}$. The ash was dissolved in $6 \mathrm{M}-\mathrm{HCl}$, evaporated to dryness on a water bath, re-dissolved in concentrated $\mathrm{HCl}$ and again evaporated to dryness. The dry residue was dissolved in warm $6 \mathrm{~m}-\mathrm{HCl}$, filtered, washed and made up to volume. The solution obtained was analysed for total $\mathrm{Ca}, \mathrm{Mg}$ and $\mathrm{P}$. Analysis of soluble $\mathrm{Ca}, \mathrm{P}$ and $\mathrm{Mg}$ in digesta was done on the supernatant fraction obtained after centrifugation at $70000 \mathrm{~g}$. The samples were then diluted with twice-distilled water and analysed. To determine the soluble fraction of these elements in faeces, $0.5 \mathrm{~g}$ of freeze-dried faeces were shaken with $9.5 \mathrm{ml}$ twice-distilled water for $\mathrm{I} h$ and the supernatant fraction, after centrifugation at $70000 \mathrm{~g}$, used for analysis.

$\mathrm{Ca}$ and $\mathrm{Mg}$ were determined using an atomic absorption spectrometer (Model no. 303, Perkin Elmer). $\mathrm{P}$ was determined colorimetrically using the $p$-aminophenolsulphate method. The method used to calculate the flows of digesta at the different sites along the intestine was described by Ben-Ghedalia et al. (1974).

\section{Statistical analysis}

An incomplete block analysis was used to compare the results obtained at six sites on the basis of samples taken from two or three cannulas in each of six rams. Because the design was not balanced, the standard error of the difference between the means is not the same for each pair of sites. The least and greatest values are given in Tables 2 and 3 . The residual standard deviation is also given as a measure of the variability of the measured values.

\section{RESULTS}

Samples taken $7 \mathrm{~m}$ from the pylorus were available from only one animal, and this should be borne in mind when changes occurring immediately before and after this site are considered.

\section{$C a, M g$ and $P$ fractions in digesta}

The concentrations of the total and soluble $\mathrm{Ca}, \mathrm{Mg}$ and $\mathrm{P}$ in digesta sampled at different sites of the small intestine are shown in Table 2. As in the previous study (Ben-Ghedalia et al. 1974) the effects of rams were found to be non-significant for all measurements. The mean values, calculated using an incomplete block analysis, showed that the cannulation site had a significant effect on the soluble $\mathrm{Ca}$ concentration and on the total and soluble concentrations of $\mathrm{Mg}$ and $\mathrm{P}$.

As the flow rate of digesta along the intestine decreased (Ben-Ghedalia et al. 1974) the concentrations of total $\mathrm{Ca}$ and $\mathrm{Mg}$ increased, suggesting that $\mathrm{Ca}$ and $\mathrm{Mg}$ on the one hand and water on the other are not absorbed in a parallel pattern. The changes in the levels of soluble $\mathrm{Ca}$ and $\mathrm{Mg}$ in digesta passing along the intestine (Table 2) are quite independent. A considerable fall in the concentration of soluble $\mathrm{Ca}$ occurs after the 
Table 2. The $p H$ and the mean concentrations of total and soluble $\uparrow$ calcium, magnesium and phosphorus (mmol/kg) in digesta sampled at different sites of the intestine and in the faeces of three sheep fitted with T-shaped cannulas

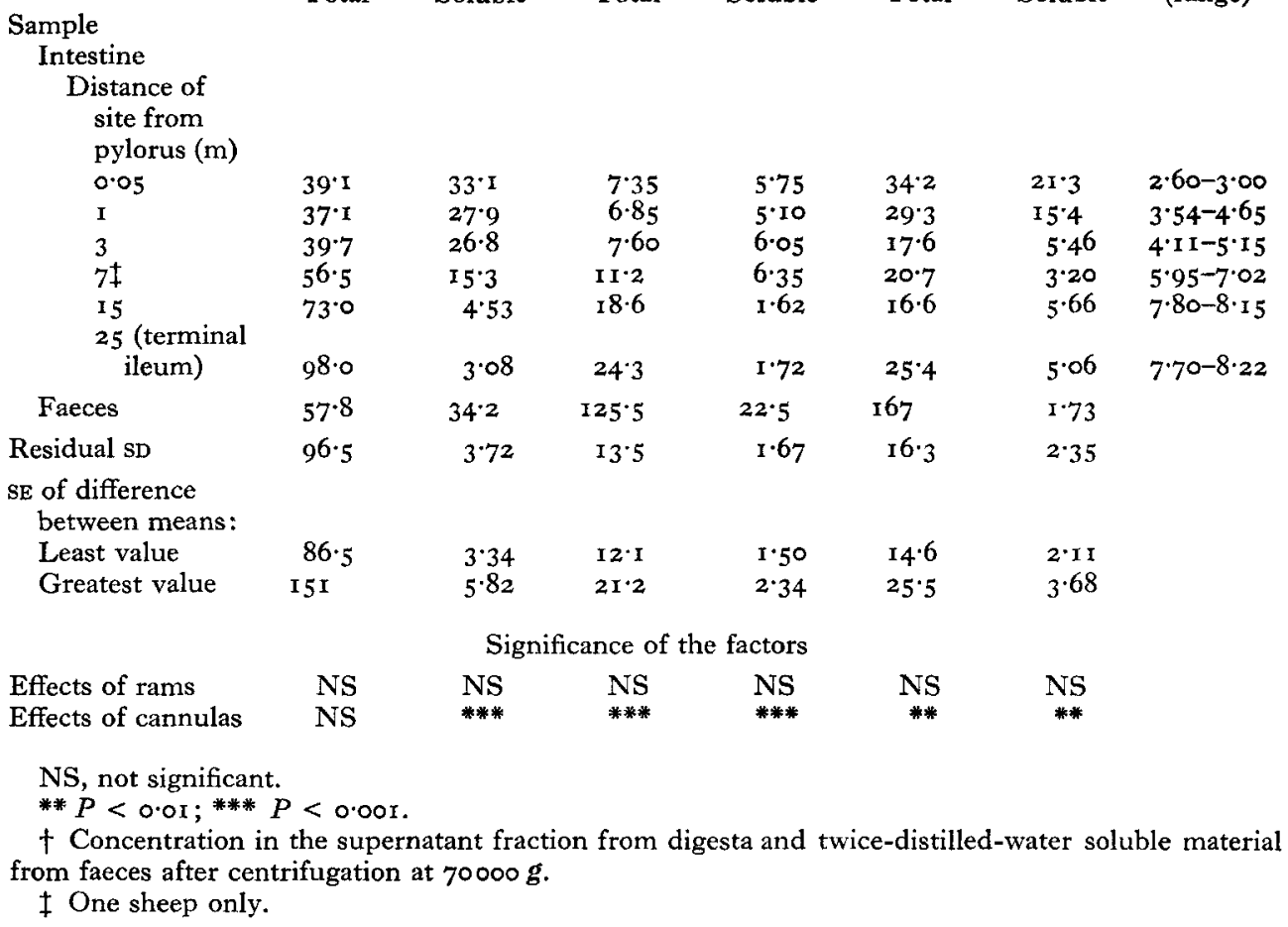

$3 \mathrm{~m}$ site and continues until the terminal ileum, while a significant decrease in soluble $\mathrm{Mg}$ occurs probably only after the $7 \mathrm{~m}$ site.

Very high concentrations of soluble $\mathrm{Ca}$ and $\mathrm{Mg}$ were obtained in the faeces. The level of soluble $\mathrm{Mg}$ was approximately four times higher, and that of $\mathrm{Ca}$ the same as the concentrations of these elements found in the digesta flowing through the upper intestine.

The soluble $\mathrm{P}$ content of digesta decreased apparently until the $7 \mathrm{~m}$ site and then remained stable until the terminal ileum. Unlike that of $\mathrm{Ca}$ and $\mathrm{Mg}$, the concentration of soluble $P$ in the faeces was very low. The solubility of the three elements, expressed as a percentage of total, decreased as the digesta flowed down the small intestine. In the duodenum $(0.05 \mathrm{~m}$ site), 84,78 and $62 \%$ of the total $\mathrm{Ca}, \mathrm{Mg}$ and $\mathrm{P}$ respectively were soluble, whereas in the digesta flowing through the terminal ileum $(25 \mathrm{~m}$ site), the values were $3 \cdot 2,7 \cdot 2$ and $19 \%$ respectively.

Up to the $7 \mathrm{~m}$ site there appeared to be a concurrent decrease in the solubility of the $\mathrm{Ca}$ and $\mathrm{P}$. Between the $7 \mathrm{~m}$ site and the $15 \mathrm{~m}$ site there was a continuous fall in the soluble $\mathrm{Ca}$ fraction but an increase in the soluble $\mathrm{P}$ fraction. In this work no distinction 


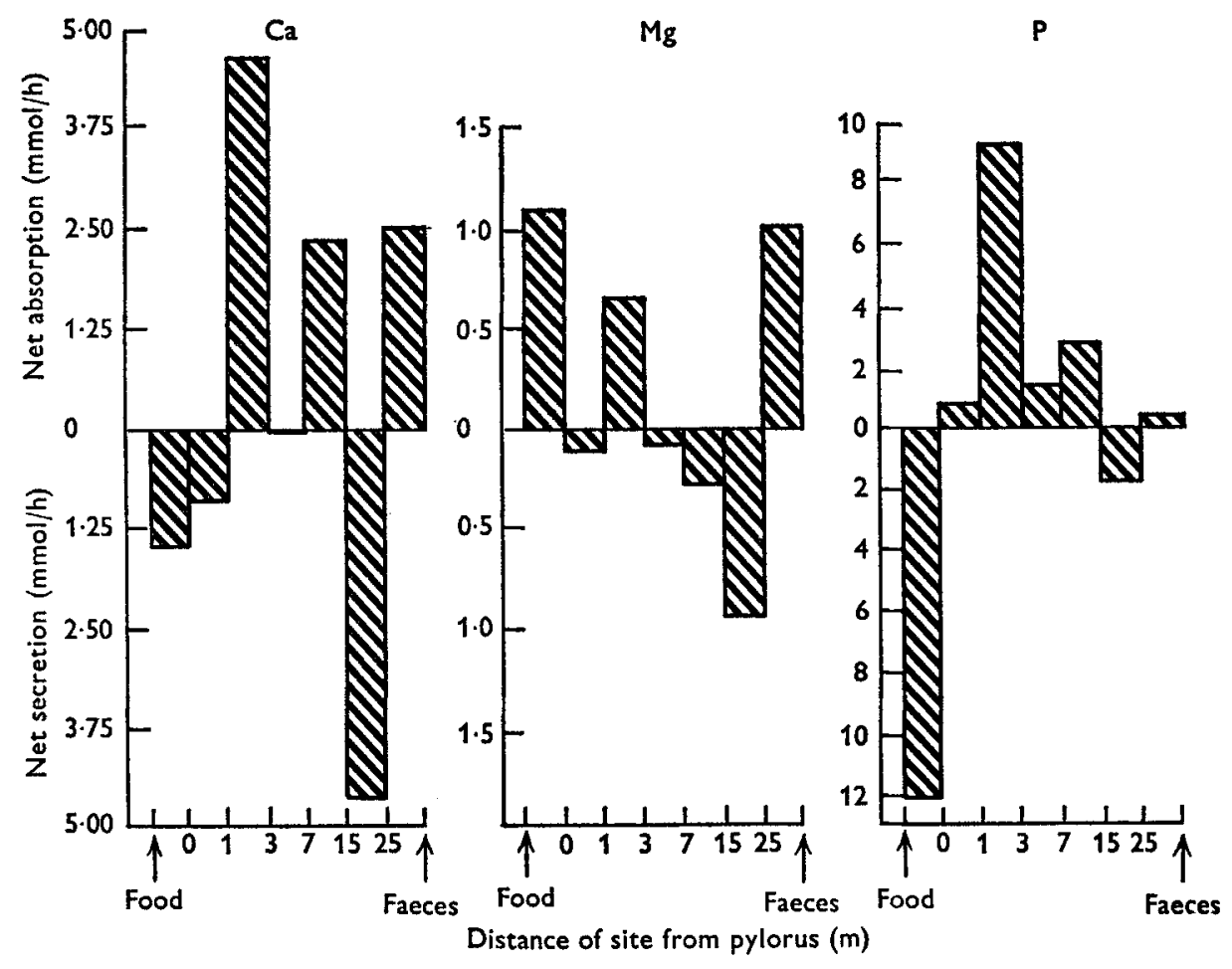

Fig. I. Net absorption and net secretion ( $\mathrm{mmol} / \mathrm{h}$ ) of calcium, magnesium and phosphorus between sites along the gastrointestinal tract posterior to the pylorus in the sheep.

was made between organic and inorganic $P$, therefore the contribution of each form to the P-soluble fraction could not be evaluated.

\section{Net exchange of $\mathrm{Ca}, \mathrm{Mg}$ and $\mathrm{P}$ along the intestine}

Table 3 shows the flow rates for total and soluble $\mathrm{Ca}, \mathrm{Mg}$ and $\mathrm{P}$ along the intestine. The net exchange of these elements is illustrated in Fig. I. The statistical analysis showed a significant effect of the cannulation sites on the total and soluble $\mathrm{Ca}$ flow rates, the soluble $\mathrm{Mg}$ flow rate and the total and soluble $\mathrm{P}$ flow rate. A substantial net absorption of $\mathrm{Mg}$ and a large net secretion of $\mathrm{P}$ occurred between the mouth and the duodenum. Following the net movements of $\mathrm{Ca}, \mathrm{Mg}$ and $\mathbf{P}$ passing along the intestine, it is clear that the sites and directions of net exchange differ for each of these three elements. While the upper small intestine ( $\mathrm{I}-3 \mathrm{~m}$ from the pylorus) seems to be the major site of $\mathrm{Ca}$ net absorption, the forestomachs and colon are the main sites for $\mathrm{Mg}$ absorption. Net absorption of $\mathrm{P}$ occurs along the section of the intestine between 0.05 and $15 \mathrm{~m}$ from the pylorus, although the most active site for $\mathrm{P}$ absorption is the upper small intestine.

Along the $\mathrm{Ist} \mathrm{m}$ of the intestine there is a certain quantitative increase of $\mathrm{Ca}$ and $\mathrm{Mg}$, but it is likely that the absolute addition of $\mathrm{Ca}$ and $\mathrm{Mg}$ into this section by the 
Table 3. Mean flow rates $(\mathrm{mmol} / \mathrm{h})$ for total and soluble $\nmid$ calcium, magnesium and phosphorus at different sites of the intestine of three sheep fitted with T-shaped cannulas

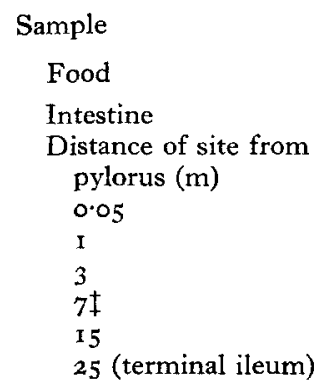

Effects of rams

Effects of cannulas

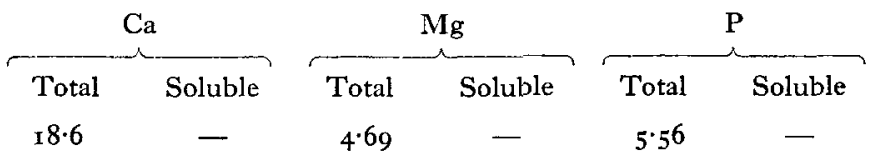

$\begin{array}{lccccc}20.1 & 17.0 & 3.57 & 2.79 & 17.5 & 10.9 \\ 21.0 & 15.7 & 3.69 & 2.73 & 16.7 & 8.79 \\ 16.4 & 11.5 & 3.30 & 2.40 & 7.46 & 2.42 \\ 16.5 & 4.48 & 3.08 & 1.75 & 6.07 & 0.93 \\ 14.0 & 0.88 & 3.37 & 0.29 & 3.19 & 1.08 \\ 18.7 & 0.60 & 4.33 & 0.31 & 5.04 & 0.96 \\ 16.2 & 0.97 & 3.28 & 0.59 & 4.65 & 0.01 \\ 2.16 & 1.61 & 0.40 & 0.17 & 2.45 & 1.19\end{array}$

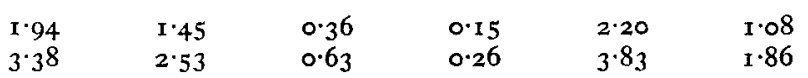

Significance of the factors

$\begin{array}{clllll}\text { NS } & \text { NS } & \text { NS } & \text { NS } & \text { NS } & \text { NS } \\ * & * * * & \text { NS } & * * * & * * * & * * *\end{array}$

NS, not significant.

$* P<0.07$; **** $P<0.000 \mathbf{1}$.

$\uparrow$ Concentration in supernatant fraction from digesta and twice-distilled-water soluble material from faeces after centrifugation at $70000 \mathrm{~g}$.

$\ddagger$ One sheep only.

common bile duct was masked by concomitant absorption. Substantial net secretion of $\mathrm{Ca}, \mathrm{Mg}$ and $\mathrm{P}$ was observed along the last $10 \mathrm{~m}$ of the small intestine.

\section{DISCUSSION}

Studies on sheep cannulated at the duodenum and ileum have contributed significantly to the knowledge of mineral absorption (Bruce et al. 1966; Rogers \& Van't Klooster, I969; Pfeffer $e t$ al. 1970). However, it is impossible from the results of these studies to assess the net changes which occur in the different parts of the small intestine. As the small intestine appears to be the major site for $\mathrm{Ca}$ and $\mathrm{P}$ absorption in cows (Rogers \& Van't Klooster, 1969) and sheep (Phillipson \& Storry, 1965; Pfeffer et al. x 970 ) the net absorption and net secretion of $\mathrm{Ca}, \mathrm{Mg}$ and $\mathrm{P}$ at sites along the intestine were studied in this work.

The solubility of minerals in the gut is one of the main factors affecting their absorption. Van't Klooster ( 1967 ) has shown that $90 \%$ of the total $\mathrm{Ca}$ and $\mathrm{Mg}$ and $73 \%$ of the total $\mathrm{P}$ passing to the duodenum of cows is in a soluble form, in comparison to 12,34 and $7 \%$ of the total $\mathrm{Ca}, \mathrm{Mg}$ and $\mathrm{P}$ respectively flowing through the ileum. The values obtained in this work are comparable.

The rise of $\mathrm{pH}$ as the digesta advances along the intestine is accompanied by a 
concomitant decrease in the solubility. The pancreatic juice flowing into the section of the intestine $0.05^{-1} \mathrm{~m}$ from the pylorus affects to some extent the solubility of these minerals (Kay, 1969), but it seems that the intestinal secretion acts as the major factor in decreasing the soluble amounts of $\mathrm{Ca}, \mathrm{Mg}$ and $\mathrm{P}$ in digesta flowing through the lower parts of the intestine. The effect of $\mathrm{pH}$ on the amount of soluble $\mathrm{Mg}$ in digesta, however, is not as marked.

This study has shown that the upper small intestine is the main site for $\mathrm{Ca}$ absorption, although this process continues to some extent up to the $15 \mathrm{~m}$ site. These results are compatible with those of Phillipson \& Storry (1965), who studied the absorption of $\mathrm{Ca}$ and $\mathrm{Mg}$ from solutions by isolated sections of the small intestine of the sheep. In addition, they found that no absorption occurred in the duodenum or in the terminal ileum, which agrees with the results presented here. Scott (1965) has shown that both $\mathrm{Ca}$ and $\mathrm{Mg}$ were absorbed from inorganic solutions placed in ileal loops of the sheep. However, in those experiments in which the concentrations of $\mathrm{Ca}$ and $\mathrm{Mg}$ were close to those found in digesta passing along the ileum, very little net absorption occurred, and in some instances a net secretion of $\mathrm{Mg}$ and $\mathrm{Ca}$ was found. The localization of the upper small intestine as the major site for Ca absorption in different species such as the horse (Schryver, Craig, Hintz, Hogue \& Lowe, 1970) and the rat (Sernka \& Borle, 1969) is undoubtedly connected with the solubility of $\mathrm{Ca}$ in this area.

Jones \& Mackie (1959), studying Ca secretion into the gut of the sheep, showed that after intravenous injection of ${ }^{45} \mathrm{Ca}$, a considerable amount of the tracer was recovered in the lower half of the small intestine. In the present study, approximately $4.75 \mathrm{mmol} \mathrm{Ca} / \mathrm{h}$ was found to be secreted in the lower $10 \mathrm{~m}$ of the small intestine. It would appear that the upper part of the small intestine is mainly a site of absorption whereas the lower part is apparently a site of secretion. In an experimental system of duodenal-ileal cannulated sheep, the $\mathrm{Ca}$ absorbed in the upper small intestine may be masked quantitatively by the endogenous secretions in the lower part. This may explain the very slight quantitative changes in $\mathrm{Ca}$ flowing through the small intestine found by Pfeffer et al. (1970).

The present results demonstrate that a substantial amount of the ingested $\mathrm{Mg}$ was absorbed before the duodenum. As the rumen epithelium appears to be impermeable to $\mathrm{Mg}^{2+}$ (Phillipson \& Storry, 1965) and no net absorption of $\mathrm{Mg}$ occurs in the abomasum and duodenum (Care \& Van't Klooster, 1965 ), it is possible that the omasum is the site of $\mathrm{Mg}$ absorption. Appreciable net absorption of $\mathrm{Mg}$ before the duodenum has been reported by Rogers \& Van't Klooster (I969), Pfeffer et al. (1970) and Kemp, Van't Klooster, Rogers \& Guerink (1973). The net movement of $\mathrm{Mg}$ in the upper small intestine found in this work, although not statistically significant, agrees with the findings of Care \& Van't Klooster (1965) which showed that Mg was absorbed from Thiry Vella loops located 3 and $10 \mathrm{~m}$ from the pylorus. However, high dietary levels of $\mathrm{Mg}$ would increase the relative importance of the forestomachs as the main site of $\mathrm{Mg}$ absorption (Kemp et al. 1973). The colon was shown to be another important site of $\mathrm{Mg}$ absorption. The proportion of soluble $\mathrm{Mg}$ in faeces was very low, but the results in Table 2 showed that the concentration of soluble $\mathrm{Mg}$ in the faeces was 
about four times higher than in digesta passing through the upper small intestine. As the formation of the faecal pellets is connected with an intense absorption of water as the digesta passes along the colon, it is clear that this process also concentrates solutes and this would facilitate the absorption (passive) of $\mathrm{Mg}$ and possibly other elements from the colon. Net absorption of $\mathrm{Mg}$ from the large intestine was also reported by Pfeffer et al. (1970) and Rook (1972). By comparison, in the rat the upper small intestine seems to be the major site of Mg absorption (Urban \& Schedl, I969; Aldor \& Moore, 1970).

Large volumes of saliva are secreted continuously by the sheep, up to $16 \mathrm{l} / \mathrm{d}$. Assuming that the $\mathrm{P}$ content of saliva is about $16.2 \mathrm{mmol} / \mathrm{l}$ (Kay, 1960), the addition of about $200 \%$ of $\mathrm{P}$ between the mouth and duodenum would be expected. In view of the fact that the reticulo-rumen and the omasum appear to be impermeable to $\mathrm{P}$ (Wright, I955), it seems that this increase in $P$ could be an absolute gain. Substantial gains of $P$ between mouth and duodenum were reported also by Bruce et al. (1966) and Pfeffer et al. (1970). It is generally accepted that $\mathrm{P}$ absorption occurs mainly in the intestine but very little information concerning $\mathrm{P}$ absorption from sections of the intestine of the sheep is available. The results presented in this paper suggest that an appreciable amount of $P$ is absorbed from the upper small intestine. About $339 \mathrm{mmol}$ $\mathrm{P} / \mathrm{d}$ were apparently absorbed from the section of the intestine $0.05^{-1} 5 \mathrm{~m}$ from the pylorus, which is $2 \cdot 5$ times the quantity that was ingested.

The authors gratefully thank Dr A. Tadmor for the cannulation of the sheep, Mr G. E. Pollott for the statistical help and Mr N. McMeniman for assistance in preparing the manuscript.

\section{REFERENCES}

Aldor, T. A. M. \& Moore, E. W. (1970). Gastroenterology 59, 745.

Ben-Ghedalia, D., Tagari, H., Bondi, A. \& Tadmor, A. (1974). Br. F. Nutr. 31, 125.

Bruce, J., Goodall, E. D., Kay, R. N. B., Phillipson, A. T. \& Vowles, L. E. (1966). Proc. R. Soc. B 166, 46.

Care, A. D. \& Van't Klooster, A. Th. (1965). I. Physiol., Lond. 177, 74.

Field, A. C. ( т 96 r). Br. F. Nutr. 15, 349.

Jones, H. G. \& Mackie, W. S. (1959). Br. F. Nutr. x3, 355.

Kay, R. N. B. (1960). F. Physiol., Lond. 150, 5 I 5 .

Kay, R. N. B. (1969). Proc. Nutr. Soc. 28, 140.

Kemp, A., Van't Klooster, A. Th., Rogers, P. A. M. \& Gucrink, J. H. (1973). Neth. F. agric. Sci. 2r, 44.

Pfeffer, E., Thompson, A. \& Armstrong, D. G. (1970). Br. F. Nutr. 24, 197.

Phillipson, A. T. \& Storry, J. E. (1965). F. Physiol., Lond. 18r, I30.

Ricketts, R. E., Weinman, D. E., Campbell, J. R. \& Thumbleson, M. E. (1970). Am. F. vet. Res. 3I, 1023.

Rogers, P. A. M. \& Van't Klooster, A. Th. (1 969). Meded. LandbHoogesch. Wageningen $11,26$.

Rook, J. A. F. (1972). In Production Disease in Farm Animals P. I4 [J. M. Payne, K. G. Hibbitt and B. F. Sansom, editors]. London: Baillière Tindall.

Schryver, H. F., Craig, P. H., Hintz, H. F., Hogue, D. E. \& Lowe, J. E. (1970). F. Nutr. 100, 1127.

Scott, D. (1965). Q. Fl exp. Physiol. 50, 3 × 2.

Sernka, T. J. \& Borle, A. B. (1969). Proc. Soc. exp. Biol. Med. 131, I4zo.

Urban, E. \& Schedl, H. P. (1969). Proc. Soc. exp. Biol. Med. 132, I I 10.

Van't Klooster, A. Th. (1967). Meded. LandbHoogesch. Wageningen 5, 135.

Wright, E. (1955). Nature, Lond. 176, 351 .

Young, V. R., Lofgreen, G. P. \& Luick, J. R. (1966). Br. F. Nutr. 20, 795. 